\title{
Acetic acid dressings: Finding the Holy Grail for infected wound management
}

\author{
Kapil S. Agrawal, Anup Vidyadhar Sarda, Raghav Shrotriya, Manoj Bachhav, Vinita Puri, \\ Gita Nataraj ${ }^{1}$ \\ Departments of Plastic Surgery and ${ }^{1}$ Microbiology, Seth GS Medical College and KEM Hospital, Mumbai, Maharashtra, India
}

Address for correspondence: Dr. Anup Vidyadhar Sarda, Department of Plastic Surgery, Old Building, $2^{\text {nd }}$ Floor, Seth GS Medical College and KEM Hospital, Dr. E Borges Road, Parel (e), Mumbai - 400 012, Maharashtra, India. E-mail: dranupsarda@gmail.com

\section{ABSTRACT}

Background: Wounds have since long, contributed majorly to the health-care burden. Infected long-standing non-healing wounds place many demands on the treating surgeon and are devastating for the patients physically, nutritionally, vocationally, financially, psychologically and socially. Acetic acid has long been included among agents used in the treatment of infected wounds. In this study, we have evaluated the use of acetic acid for topical application in the treatment of infected wounds. Materials and Methods: A total of 100 patients with infected wounds were treated with topical application of $1 \%$ acetic acid as dressing material after appropriate cleaning. A specimen of wound swab was collected before first application and further on days 3, 7, 10 and 14. Daily dressings of wounds were done similarly. Minimum inhibitory concentration (MIC) of acetic acid against various organisms isolated was determined. Results: The patients treated ranged between 9 and 60 years, with the mean age 33 years. Nearly $70 \%$ of patients were male. Aetiologies of wounds: infective 35, diabetic 25, trauma 20, burns 10, venous ulcers 5 and infected graft donor site 5. Various microorganisms isolated include Pseudomonas aeruginosa (40\%), Staphylococcus aureus (2\%), Acinetobacter (12\%), Escherichia Coli $(5 \%)$, Proteus mirabilis (3\%), Klebsiella (18\%), methicillin-resistant S. aureus (10\%), Streptococcus (2\%) and Enterococcus (1\%), Citrobacter (1\%). Few wounds (6\%) also isolated fungi. About $28 \%, 64 \%$ and $8 \%$ of patients isolated no growth on culture after 7,14 and 21 days, respectively. MIC of all isolated organisms was $\leq 0.5 \%$. Conclusion: $\mathrm{pH}$ of the wound environment plays a pivotal role in wound healing. Acetic acid with concentration of $1 \%$ has shown to be efficacious against wide range of bacteria as well as fungi, simultaneously accelerating wound healing. Acetic acid is non-toxic, inexpensive, easily available and efficient topical agent for effective elimination of wound infections caused due to multi-drug resistant, large variety of bacteria and fungus.

\section{KEY WORDS}

Acetic acid; dressing material; infected wounds; minimum inhibitory concentration

\begin{tabular}{|l|l|}
\hline \multicolumn{2}{|c|}{ Access this article online } \\
\hline Quick Response Code: & Website: \\
\hline & www.ijps.org \\
\cline { 2 - 2 } & Dol: \\
\hline
\end{tabular}

This is an open access article distributed under the terms of the Creative Commons Attribution-NonCommercial-ShareAlike 3.0 License, which allows others to remix, tweak, and build upon the work non-commercially, as long as the author is credited and the new creations are licensed under the identical terms.

For reprints contact: reprints@medknow.com

How to cite this article: Agrawal KS, Sarda AV, Shrotriya R, Bachhav M, Puri V, Nataraj G. Acetic acid dressings: Finding the Holy Grail for infected wound management. Indian J Plast Surg 2017;50:273-80. 


\section{INTRODUCTION}

W ounds have since long, contributed majorly to the health-care burden. Infected long-standing non-healing wounds place many demands on the treating surgeon and have necessitated the use of various topical agents for dressings, ranging from simple saline gauze to expensive modern materials. Such wounds are even more devastating for the patients as they are affected physically (pain and bleeding), nutritionally (loss of proteins and electrolytes), vocationally (loss of job due to long absenteeism), financially (cost of protracted dressings and repeated hospital visits), psychologically (loss of self-confidence, depression) and socially (breakdown of personal and professional relationships and dependence on others). Expedited wound recovery is therefore desirable to reduce this enormous burden from the health-care system.

Bacterial and fungal infections are a major hindrance in the healing of chronic wounds. Conventionally, infections have been treated by systemic antibiotics, but in the majority of diabetic and chronic non-healing wounds, these systemic preparations are not helpful. Many of the wound treatment modalities being used presently have limitations due to cost factors, availability and development of resistance or adverse effects.

As per literature, a major factor in the healing of an infected wound is its $\mathrm{pH}$. Alkaline milieu has been found to be a prerequisite for the growth of most of the pathogens. ${ }^{[1-3]}$ With the healing of the wound, there is a shift in $\mathrm{pH}$ towards neutral. ${ }^{[4-6]} \mathrm{pH}$ modification can be the key determinant in reducing infection. Historically, acetic acid has been used to treat wounds with Pseudomonas infection. In the present study, the authors have aimed at evaluating the antibacterial and antifungal spectrum of acetic acid in the treatment of infected wounds, especially the multi-drug resistant, chronic non-healing and diabetic wounds, and attempted to standardise the concentration of acetic acid for dressings using minimum inhibitory concentration (MIC) and minimum bactericidal concentration (MBC) of acetic acid for various pathogens.

\section{MATERIALS AND METHODS}

Thisisa prospectiveanalysis of 100 patients havinginfected wounds which were treated at a tertiary care centre over a period of 2 years (October 2013-October 2015). Most of the patients included in the study had already been treated by standard techniques such as saline, povidone-iodine, eusol and hydrogen peroxide. Inclusion criteria took into account a failed attempt by standard techniques to weed out wound infection by referring doctor. Patients having systemic manifestations of infection were excluded from the study. Rest of all wounds were included in the study.

Approval was obtained from the Institutional Ethics Committee. Various dilutions of acetic acid were tested against common bacterial flora in our hospital to determine the appropriate concentration of acetic acid to inhibit the growth of these pathogens [Table 1]. Inoculum size of an overnight culture was adjusted to McFarland 0.5 corresponding to $1.5 \times 10^{8} \mathrm{cfu} / \mathrm{ml}$ for all dilutions. As per results the results, $1 \%$ acetic acid was chosen for dressings.

All patients were explained the procedure and written informed consent was obtained. Same protocol was followed in all patients for dressings. After removal of the dressing, immersion bath with $0.1 \%$ acetic acid was given for 15 min since this solution, although not bactericidal, helps in creating an acidic environment. Then, wounds were cleaned with normal saline. After that, the wound was covered with non-adhesive sterile Vaseline gauze, over which gauze soaked in $1 \%$ acetic acid solution was kept and then wound was closed with sterile dressings. About $1 \%$ acetic acid was prepared from diluting acetic acid with normal saline. During this period, no systemic antibiotics were given to the patients.

For each wound, the swab was collected before using acetic acid dressing and further on days 3, 7, 10 and 14 . This was processed for isolation of bacteria and fungi. Clinical isolates were tested for minimum inhibitory concentration (MIC) and minimum bactericidal concentration (MBC) of acetic acid using the standard

\begin{tabular}{|c|c|c|c|c|c|}
\hline \multirow{2}{*}{$\begin{array}{l}\text { Bacterial } \\
\text { strains tested }\end{array}$} & \multicolumn{5}{|c|}{ Concentration of acetic acid } \\
\hline & $1 \%$ & $0.5 \%$ & $0.25 \%$ & $0.125 \%$ & $0.0625 \%$ \\
\hline $\begin{array}{l}\text { Escherichia } \\
\text { coli }\end{array}$ & No growth & No growth & No growth & Growth & Growth \\
\hline $\begin{array}{l}\text { Proteus } \\
\text { mirabilis }\end{array}$ & No growth & No growth & Growth & Growth & Growth \\
\hline Streptococcus & No growth & No growth & No growth & No growth & Growth \\
\hline Enterococcus & No growth & No growth & No growth & Growth & Growth \\
\hline
\end{tabular}


technique (tube dilution) by the microbiologist. Isolated bacteria were also tested for antibiotic sensitivity.

For standardisation, $\mathrm{pH}$ of various dilutions of vinegar $(4 \%, 1 \%$ and $0.1 \%)$ was measured using digital $\mathrm{pH}$ meter (pHep ${ }^{\circledR}$-Accuracy $\pm 0.120 \mathrm{C} / 68 \mathrm{~F}$ ) [Table 2]. Wound surface $\mathrm{pH}$ monitoring was performed using $\mathrm{pH}$ indicator strips.

The wounds were assessed clinically for the amount of discharge, odour, wound size and quality of granulation tissue on alternate days and photographs were taken after proper consent of the patients. No growth on culture with uniform layer of granulation was considered as the primary end point of treatment and patient was posted either for skin grafting or flap cover surgery as per need.

The data collected has been subjected to statistical analysis using SPSS software version 22 (IBM Corp. Released 2013. IBM SPSS Statistics for Windows, Version 22.0. Armonk, NY:IBM Corp.) and various descriptive statistics will be used to calculate frequencies, percentage, mean and standard deviation. Numerical data such as age, MIC and MBC has been expressed as mean, whereas categorical data such as sex, aetiology of wound, isolated organisms, number of days to achieve no growth on culture and uniform coverage of wound by granulation has been expressed as percentages.

\section{RESULTS}

The mean age of patients treated was 33 years (range 9-60 years) with 70\% were male. Common aetiologies of wounds were infection and trauma as shown in Figure 1.

Various microorganisms that were isolated from wounds are shown in Table 3, which shows Pseudomonas being the most common isolate followed by Klebsiella and Acinetobactor. Fungi were isolated from $6 \%$ of wounds.

The results of MIC and MBC of acetic acid against these pathogens are shown in Tables 4 and 5 show that $>0.5 \%$ concentration was sufficient to inhibit the growth of bacteria and fungi. The mentioned MIC and MBC values in Tables 4 and 5 represent the mean value for a particular organism. Isolated bacteria also underwent antibiotic sensitivity tests and majority were found to be resistant to commonly tested antibiotics.

Patients were treated for a variable period of 7-21 days with $1 \%$ acetic acid. Majority of the patients (64 out of 100 )
Table 2: $\mathrm{pH}$ of various concentrations of acetic acid

\begin{tabular}{ll} 
Solution & $\mathbf{p H}$ \\
\hline $4 \%$ acetic acid & 2.0 \\
$1 \%$ acetic acid & 2.5 \\
$0.1 \%$ acetic acid & 4.8 \\
\hline
\end{tabular}

Table 3: Percentage of isolated organisms

\begin{tabular}{|c|c|c|}
\hline \multicolumn{3}{|l|}{ Gram-negative } \\
\hline \multicolumn{3}{|l|}{ Pseudomonas aerugin - $40 \%$} \\
\hline \multicolumn{3}{|c|}{ Klebsiella - $18 \%$} \\
\hline \multicolumn{3}{|c|}{ Acinetobacter baumannii - $12 \%$} \\
\hline \multicolumn{3}{|c|}{ Escherichia coli - $5 \%$} \\
\hline \multicolumn{3}{|l|}{ Proteus mirabilis - $3 \%$} \\
\hline \multicolumn{3}{|l|}{ Enterobacter-1\% } \\
\hline \multicolumn{3}{|l|}{ Citrobacter - 1\% } \\
\hline \multicolumn{3}{|l|}{ Gram-positive } \\
\hline \multicolumn{3}{|l|}{ MRSA - $10 \%$} \\
\hline \multicolumn{3}{|c|}{ Staphylococcus aureus - $2 \%$} \\
\hline \multicolumn{3}{|c|}{ Streptococcus - $2 \%$} \\
\hline \multicolumn{3}{|l|}{ Fungi - $6 \%$} \\
\hline \multicolumn{3}{|c|}{ MRSA: Methicillin-resistant Staphylococcus aureus } \\
\hline \multicolumn{3}{|c|}{$\begin{array}{l}\text { Table 4: Mean minimal inhibitory concentration and mean } \\
\text { bactericidal concentration of acetic acid for various bacterial } \\
\text { strains isolated }\end{array}$} \\
\hline Bacterial strains tested & MIC of acetic acid (\%) & $M B C(\%)$ \\
\hline Streptococcus & 0.0625 & 0.125 \\
\hline Staphylococcus aureus & 0.0625 & 0.125 \\
\hline Pseudomonas aeruginosa & 0.125 & 0.25 \\
\hline Klebsiella & 0.125 & 0.25 \\
\hline Acinetobacter & 0.125 & 0.25 \\
\hline Escherichia coli & 0.125 & 0.25 \\
\hline Enterococcus & 0.125 & 0.25 \\
\hline MRSA & 0.125 & 0.25 \\
\hline Proteus mirabilis & 0.25 & 0.5 \\
\hline Citrobacter & 0.25 & 0.5 \\
\hline
\end{tabular}

MRSA: Methicillin-resistant Staphylococcus aureus

Table 5: Mean minimal inhibitory concentration of acetic acid for various fungal strains isolated

\begin{tabular}{lc}
\hline Fungal strains tested & MIC of acetic acid (\%) \\
\hline Candida albicans & \\
Standard strain & 0.5 \\
Clinical isolate & 0.5 \\
Aspergilus niger & 0.5 \\
Aspergillus fumigatus & 0.5 \\
Cryptococcus neoformans & 0.5 \\
\hline
\end{tabular}

recorded no growth on culture after 14 days. Twenty-eight out of 100 patients recorded no growth on culture after 7 days. Eight patients of compound fractures of the lower limb and a few fungal infections required treatment for 21 days before no organism was isolated.

There was a decrease in wound size, surrounding inflammation and induration after treatment with acetic acid, suggestive of wound healing. There was a 


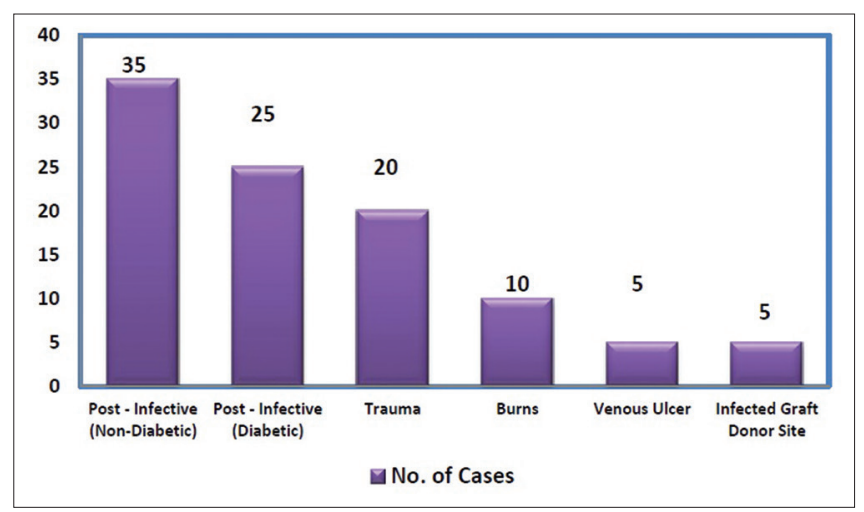

Figure 1: Etiology of wounds

marked improvement in terms of discharge, odour and granulation tissue. Apart from stinging sensation on application complained by few patients, there were no significant side effects of the use of acetic acid for dressings. Infected skin grafting donor sites also showed a decrease in the amount of soakage after treatment with $1 \%$ acetic acid and healed spontaneously without the need of grafting. The average $\mathrm{pH}$ of infected wounds was alkaline ( $\mathrm{pH}-9)$ while the wound with improved granulation tissue showed $\mathrm{pH}$ of 7 .

Few representative cases are discussed below:

\section{Case 1}

A 45-year-old diabetic female with wound over the dorsum of the foot with exposed tendons was managed with daily dressings using acetic acid. The wound improved remarkably in 10 days with uniform healthy granulation tissue and finally covered using the skin graft, without the need of flap cover [Figure 2a-e].

\section{Case 2}

A 68-year-old diabetic male presented with an infected wound over the right foot with external fixator 20 days after crush injury. The patient was given regular dressings using acetic acid and the wound improved with healthy granulation tissue within 14 days. The wound was eventually covered using a split-thickness skin graft as the patient was not fit for major surgery [Figure 3a-e].

\section{Case 3}

A 32-year-old male patient presented with infected skin graft donor site with fungal growth [Figure 4a]. The patient had already received first oral and then intravenous antifungal drug (Amphotericin B), but was not responding to the treatment. The patient was started on daily acetic acid dressings. He was not given any antifungal or antibacterial drugs during this period. The wound improved significantly with clearance of fungal infection and was ready for skin grafting by day 21 [Figure 4a-c].

\section{Case 4}

A 45-year-old male patient presented with compound fracture of tibia and fibula with copious purulent discharge and exposed fracture fragments. He was treated using $1 \%$ acetic acid dressing for 14 days, before cover using medial gastrocnemius and hemisoleus muscle flap [Figure 5a-d].

\section{DISCUSSION}

Acetic acid lowers the $\mathrm{pH}$ of the wound, consequently affecting the healing process of the wound by several mechanisms [Figure 6]. Since most pathogenic bacteria require a pH value higher than 6 , their growth is inhibited by application of acetic acid ${ }^{[7,8,9]}$. It has been found that lowering of $\mathrm{pH}$ in the wound leads to reduction in bacterial protease activity ${ }^{[10,11,12]}$. Low $\mathrm{pH}$ in wound surroundings promotes wound healing and oxygen radical production for killing of bacteria by improving cell oxygenation by Bohr effect ${ }^{[4,13,14]}$. It also leads to increase in macrophage fibroblast activity and reduces toxicity of bacterial end products ${ }^{[15,16,17]}$. All these actions collectively lead to rapid decontamination with improved granulation.

In 1916, Taylor ${ }^{[18]}$ reported that application of a $1 \%$ solution of acetic acid for 2 weeks to purulent war wounds infected with "Bacillus pyocyaneus" led to the elimination of the organism. Previous studies carried out by Phillips et al. in 1968, ${ }^{[19]}$ Milner in $1992^{[20]}$ and Nagoba et al. in $2008^{[21]}$ have demonstrated the efficacy of diluted acetic acid using concentrations ranging from $1 \%$ to $5 \%$. It was shown to be effective against Pseudomonas aeruginosa from the burn and other skin wounds. Millner et al. used $0.5 \%$ acetic acid for wound irrigation to create an unfavourable environment for bacterial growth.

In our study, we have found that acetic acid is effective not only against Pseudomonas but also against a wide variety of microorganisms, which was not the finding in numerous other studies. ${ }^{[18-20]}$ Acetic acid is also effective in inhibiting the growth of fungus, for which no previous studies were found on an extensive literature search. This has potentially expanded the spectrum of coverage of acetic acid for wound dressing.

The mechanism of inhibition of fungal growth by acetic acid is generally not considered a pH -related phenomenon. 


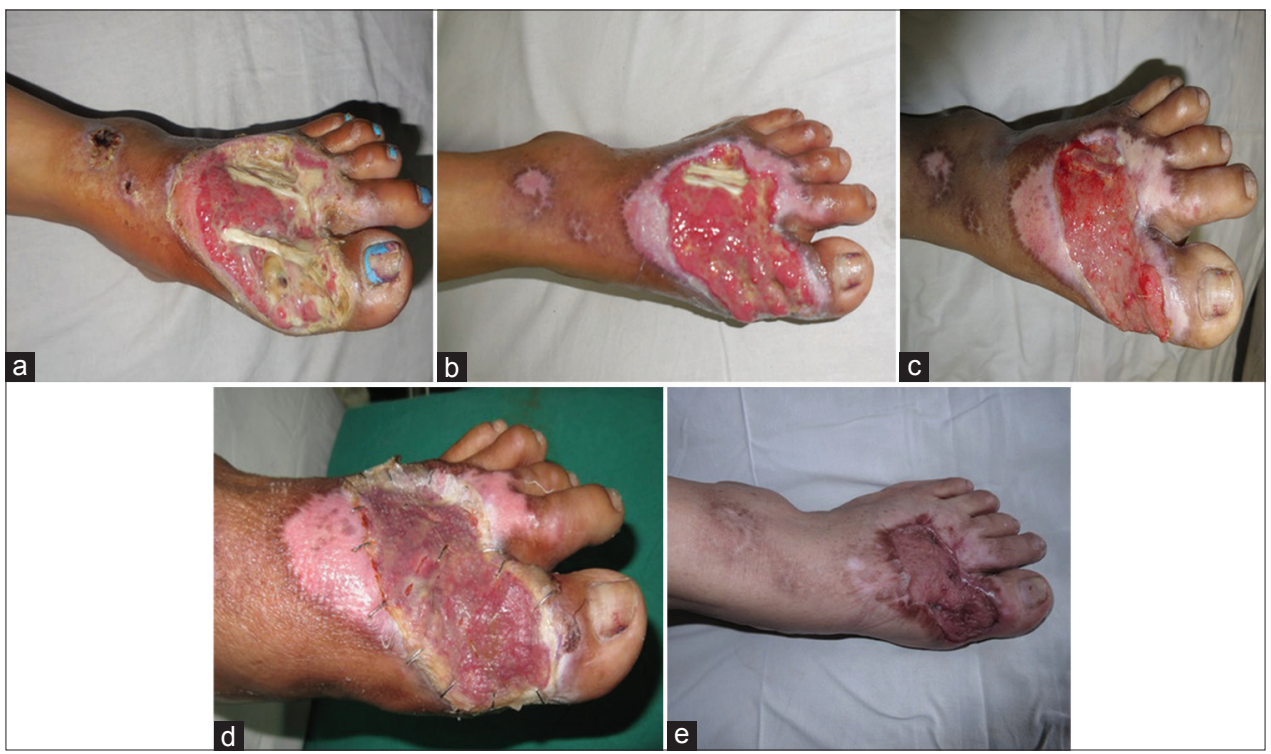

Figure 2: (a) Forty five $y / F$, diabetic patient with post-infective wound on dorsum of foot on presentation, before treatment with acetic acid. (b) Wound after 10 days of treatment with $1 \%$ acetic acid. (c) Wound after 20 days of treatment with $1 \%$ acetic acid, just prior to skin grafting. (d) Wound at second check dress after skin grafting. (e) Well settled graft, three months post-operatively
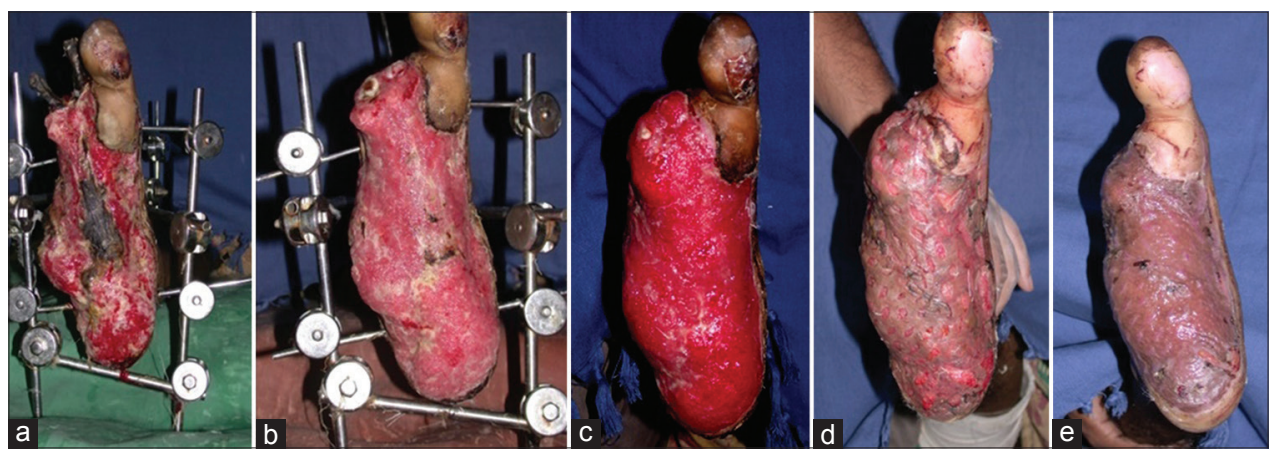

Figure 3: (a) Sixty eight y/M, diabetic patient with post crush injury infected wound on right foot on presentation, before treatment with acetic acid. (b) Wound after 7 days of treatment with $1 \%$ acetic acid. (c) Wound after 14 days of treatment with $1 \%$ acetic acid, just prior to skin grafting. (d) Wound at second check dress after skin grafting. (e) Well settled graft, 1 month post-operatively

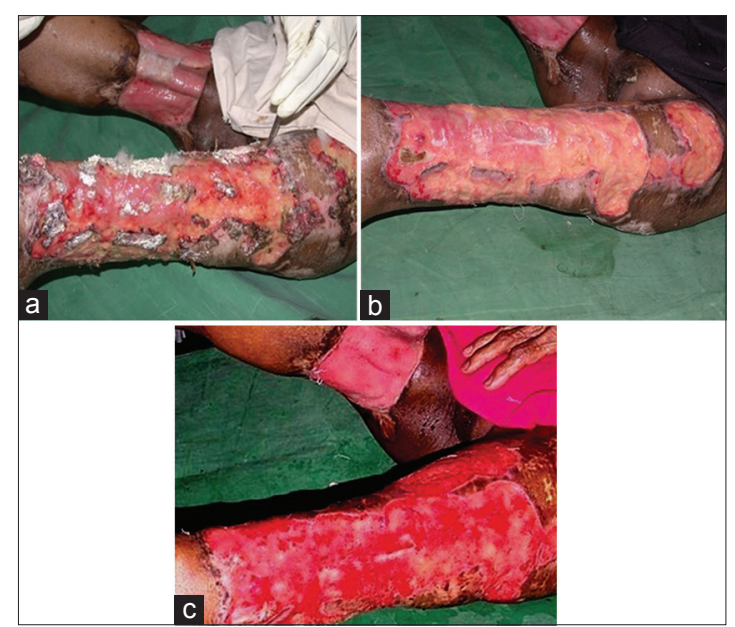

Figure 4: (a) Thirty two $\mathrm{y} / \mathrm{M}$, with fungal infection of skin grafting donor site, on presentation. (b) Wound after 10 days of treatment with $1 \%$ acetic acid. (c) Wound after 21 days of treatment with 1\% acetic acid, ready for cover with skin graft
Organic acids resulting a decreasing in $\mathrm{pH}$ value, this may influence the growth by acidifying the cell, which will consume a great amount of energy to maintain the intracellular $\mathrm{pH}$ homeostasis. Other explanations have also been proposed including the membrane disruption, the interruption of metabolic reactions, and the accumulation of toxic anions. ${ }^{[22]}$ Despite growth inhibition by acetic acid, the fungus was able to grow in a normal medium when acetic acid was eliminated, implying that the growth inhibition may be resulted from an acetic acid-mediated inhibition of respiration than a structural damage of cell. Due to these reasons acetic acid has been long used as preservative for food to prevent fungal growth. ${ }^{[23]}$

Bacteria isolated were resistant to commonly used antibiotics proving the efficacy of acetic acid against 


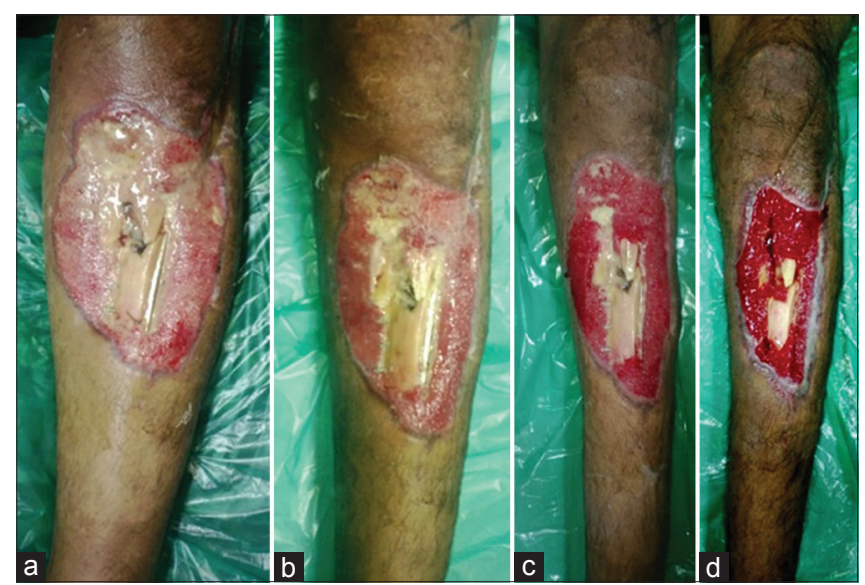

Figure 5: Forty five $\mathrm{y} / \mathrm{M}$ with compound fracture of tibia-fibula on presentation, with copious purulent discharge and exposed fracture fragments. (b) Wound after 3 days of treatment with 1\% acetic acid. (c) Wound after 7 days of treatment with $1 \%$ acetic acid. (d) Wound after 14 days of treatment with $1 \%$ acetic acid, prior to flap cover

multiple drug-resistant bacteria. Eliminating these infections by using only topical acetic acid avoided the need of antibiotics and morbidity associated with it.

This study further shows that concentration of $1 \%$ acetic acid is sufficient for halting the growth of most of the common bacteria and fungi. Very high concentrations may cause burning sensation and skin irritation, and are generally not required. Some studies have suggested cytotoxic effects of acetic acid in vitro, but clinically no such effects have been found. ${ }^{[24]}$ Various other acids have been tried for acidification of wound such as ascorbic acid, ${ }^{[25]}$ citric acid, ${ }^{[26-28]}$ boric acid, ${ }^{[29]}$ thus reinforcing the effects of low pH in wound healing. Honey has also been described for decreasing $\mathrm{pH}$ in wound dressing by Gethin and Cowman. ${ }^{[6]}$ in 2006.

Acetic acid is easily available, inexpensive and non-toxic as compared to other topical agents or systemic antibiotics. Topical agents such as $1 \%$ povidone-iodine, $3 \%$ hydrogen peroxide, and $0.5 \%$ sodium hypochlorite have been found to be cytotoxic and adversely effect the wound healing. Silver sulphadiazine has been found to cause leucopenia. More recently, Phillips et al. ${ }^{[19]}$ demonstrated the efficacy of locally applied acetic acid, as compared with either chlorhexidine or hypochlorite for the elimination of $P$. aeruginosa from the superficial skin and burn wounds in a tropical climate. Acetic acid has been found to be efficacious against multiple drug-resistant bacteria in both forms, planktonic (free-floating in broth) as well as biofilm (attached to a surface), which is of major significance since the biofilm form has been shown to play a major role in causation and maintenance

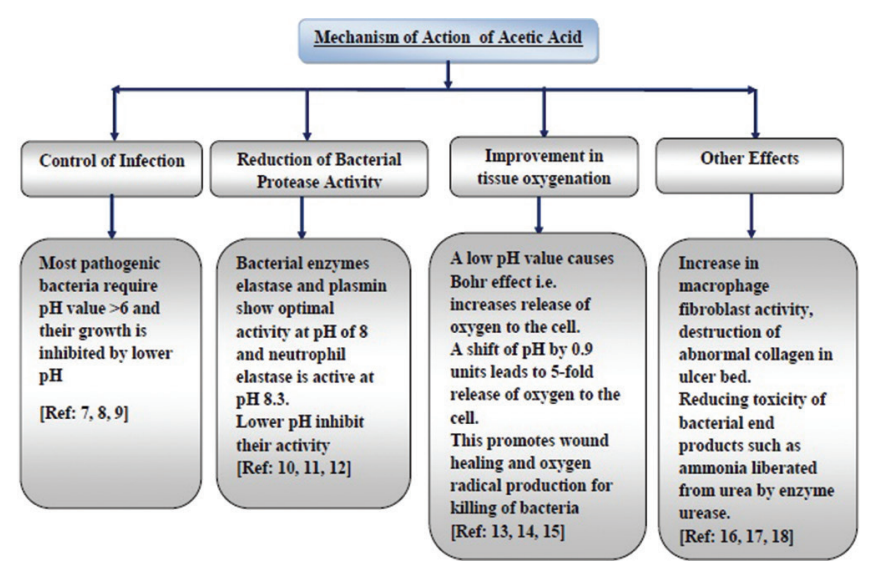

Figure 6: Mechanism of action of acetic acid in wound management

of drug-resistant bacterial infections. ${ }^{[30]}$ In this study, majority of the wounds improved within 7-14 days, which is in accordance with findings in other studies ${ }^{[18-21]}$ too.

MIC of acetic acid in this study was much less for staphylococcus and streptococcus $(0.125 \%)$ showing the sensitivity of these bacteria at very low concentrations while higher MIC was required for proteus and citrobacter $(0.25 \%)$ along with fungi $(0.5 \%)$. Previously, MIC has been evaluated only by Sloss et al..$^{[31]}$ against Pseudomonas. The maximum MIC in the present study (0.5\%) is much less as compared to Sloss et al. (2\%) and against a wider spectrum of bacteria.

Average $\mathrm{pH}$ of infected wounds was alkaline (pH-9) which was comparable to results shown by Tsukada et al. $1992(\mathrm{pH} \mathrm{8.9})^{[2]}$ and Wilson et al. in $1979(\mathrm{pH}=7.15) .^{[1]}$ The wounds with even layer of granulation were found to have average $\mathrm{pH}$ was 7.0. Authors have been using this dressing method for patients following up on out patients department (OPD) basis. The patients are taught to do dressings using $1 \%$ acetic acid at home and to follow up in OPD twice a week. A similar practice has been reported by Glen Bowen et al. from University of Utah (U.S.A.) and a patient education sheet for acetic acid dressings has also been published. ${ }^{[32]}$

In our experience, acetic acid dressings have changed the scene of our dressing room having motivated patients with clean, odourless wounds. Drug resistance does not create any panic as the dressing works with the same effect without the need of systemic antibiotic therapy. Debilitated patients not fit for prolonged surgery for flap may get away with much smaller procedures like skin grafting. 
It is certainly a weakness of the study that, the parameters of wound healing have not been compared with few of the older and newer dressing materials like silver ions containing dressing material and further studies will be required for it.

\section{CONCLUSION}

- $\mathrm{pH}$ of the wound environment plays a pivotal role in wound healing. Acetic acid can be a simple solution to a complex problem acting at the root level altering the alkaline milieu of infected wounds and breaking the barrier of multidrug resistance in diabetics and other chronic non-healing wounds

- Acetic acid with concentration of $1 \%$ has shown to be efficacious against a wide range of bacteria as well as fungi, simultaneously accelerating wound healing. We strongly recommend the use of $1 \%$ acetic acid dressings to deal with majority of infected wounds, which not only heals the wound faster but also reduces health-care cost, hospital stay and morbidity associated with systemic antibiotics

- Most of the patients can be treated and taught self-care and dressing protocol on an OPD basis. Domiciliary care keeps the patient at ease, reduces health-care cost and burden

- There is an epidemic of diabetes and related chronic non-healing wounds on limbs leading to increased number of amputations. It shows potential for decreasing the rate of amputation in difficult infections (which needs further study).

\section{Declaration of patient consent}

The authors certify that they have obtained all appropriate patient consent forms. In the form the patient(s) has/have given his/her/their consent for his/her/their images and other clinical information to be reported in the journal. The patients understand that their names and initials will not be published and due efforts will be made to conceal their identity, but anonymity cannot be guaranteed.

\section{Financial support and sponsorship}

Nil.

\section{Conflicts of interest}

There are no conflicts of interest.

\section{REFERENCES}

1. Wilson IA, Henry M, Quill RD, Byrne PJ. The $\mathrm{pH}$ of varicose ulcer surfaces and its relationship to healing. Vasa 1979;8:339-42.
2. Tsukada K, Tokunaga K, Iwama T, Mishima Y. The $\mathrm{pH}$ changes of pressure ulcers related to the healing process of wounds. Wounds1992;4:16-20.

3. Romanelli M, Schipani E, Piaggesi A, Barachini P. Evaluation of Surface $\mathrm{pH}$ on Venous Leg Ulcers under Allevyn Dressings. London: The Royal Society of Medicine Press; 1997.

4. Leveen HH, Falk G, Borek B, Diaz C, Lynfield Y, Wynkoop BJ, et al. Chemical acidification of wounds. An adjuvant to healing and the unfavourable action of alkalinity and ammonia. Ann Surg 1973; 178:745-53.

5. Roberts G, Hammad L, Creevy J, Shearman C, Mani R. Physical changes in dermal tissues around chronic venous ulcers. $7^{\text {th }}$ European Conference on Advances in Wound Management. J Eur Wound Manage Assoc 1997;2: 104-5.

6. Gethin G, Cowman S. Changes in Surface pH of Chronic Wounds When a Honey Dressing was used. In: Wounds UK Conference Proceedings. Wounds UK, Aberdeen; 13-15 November, 2006.

7. O'Meara S, Cullum N, Majid M, Sheldon T. Systematic reviews of wound care management: (3) antimicrobial agents for chronic wounds; (4) diabetic foot ulceration. Health Technol Assess 2000;4:1-237.

8. Stewart CM, Cole MB, Legan JD, Slade L, Vandeven MH, Schaffner DW, et al. Staphylococcus aureus growth boundaries: Moving towards mechanistic predictive models based on solute-specific effects. Appl Environ Microbiol 2002;68:1864-71.

9. Thomas LV, Wimpenny JW, Davis JG. Effect of three preservatives on the growth of Bacillus cereus, vero cytotoxigenic Escherichia coli and Staphylococcus aureus, on plates with gradients of $\mathrm{pH}$ and sodium chloride concentration. Int $\mathrm{J}$ Food Microbiol 1993;17:289-301.

10. Hoffman R, Noble J, Eagle M. The use of proteases as prognostic markers for the healing of venous leg ulcers. J Wound Care 1999;8:273-6.

11. Vermeulen $\mathrm{H}$, van Hattem JM, Storm-Versloot MN, Ubbink DT. Topical silver for treating infected wounds. Cochrane Database Syst Rev 2007;Jan 24;(1):CD005486.

12. Greener B, Hughes AA, Bannister NP, Douglass J. Proteases and $\mathrm{pH}$ in chronic wounds. J Wound Care 2005;14:59-61.

13. Hunt TK, Twomey P, Zederfeldt B, Dunphy JE. Respiratory gas tensions and $\mathrm{pH}$ in healing wounds. Am J Surg 1967;114:302-7.

14. Hunt TK, Beckert S. Therapeutical and practical aspects of oxygen in wound healing. In: Lee B, editor. The Wound Management Manual. New York: McGraw-Hill Professional; 2004. p. 44-54.

15. Hunt TK, Hopf HW. Wound healing and wound infection. What surgeons and anesthesiologists can do. Surg Clin North Am 1997;77:587-606.

16. Thomas S. Wound Management and Dressings. London, UK: Pharmaceutical Press; 1990.

17. Molan PC. Re-introducing honey in the management of wounds and ulcers - Theory and practice. Ostomy Wound Manage 2002;48:28-40.

18. Taylor K. Treatment of Bacillus pyocyaneus infection. JAMA 1916;67:1598-9.

19. Phillips I, Lobo AZ, Fernandes R, Gundara NS. Acetic acid in the treatment of superficial wounds infected by Pseudomonas aeruginosa. Lancet 1968;1:11-4.

20. Milner SM. Acetic acid to treat Pseudomonas aeruginosa in superficial wounds and burns. Lancet 1992;340:61.

21. Nagoba B, Wadher B, Kulkarni $P$, Kolhe S. Acetic acid treatment of pseudomonal wound infections. Eur J Gen Med 2008;5:104-6.

22. Hassan R, El-Kadi S, Sand M. Effect of some organic acids on some fungal growth and their toxins production. Int $\mathrm{J}$ Adv Biol 2015;2:1-11.

23. Kang HC, Park YH, Go SJ. Growth inhibition of a phytopathogenic 
fungus, Colletotrichum species by acetic acid. Microbiol Res 2003;158:321-6.

24. Lineaweaver W, Howard R, Soucy D, McMorris S, Freeman J, Crain C, et al. Topical antimicrobial toxicity. Arch Surg 1985;120:267-70.

25. Mujumdar RK. Treatment of resistant pseudomonas infection in burn patients in tropical climate using acidic medium, oxidizing agent and metronidazole. Indian J Surg 1993;55:501-7.

26. Nagoba BS, Deshmukh SR, Wadher BJ, Mahabaleshwar L, Gandhi RC, Kulkarni PB, et al. Treatment of superficial pseudomonal infections with citric acid: An effective and economical approach. J Hosp Infect 1998;40:155-7.

27. Nagoba BS, Gandhi RC, Wadher BJ, Deshmukh SR, Gandhi SP. Citric acid treatment of severe electric burns complicated by multiple antibiotic resistant Pseudomonas aeruginosa. Burns 1998;24:481-3.

28. Nagoba BS, Kulkarni PB, Wadher BJ, Kulkarni UP,
Mahabaleshwar L. Citric acid treatment of diabetic foot: A simple and effective approach. J Assoc Physicians India 2000;48:739-41.

29. Kujath $P$, Hügelschäffer $C$. Pseudomonas aeruginosa: Pathogenicity, prevention and therapeutic approaches. Zentralb Chir 1987;112:558-63.

30. Halstead FD, Rauf M, Moiemen NS, Bamford A, Wearn CM, Fraise AP, et al. The antibacterial activity of acetic acid against biofilm-producing pathogens of relevance to burns patients. PLoS One 2015;10:e0136190.

31. Sloss JM, Cumberland N, Milner SM. Acetic acid used for the elimination of Pseudomonas aeruginosa from burn and soft tissue wounds. J R Army Med Corps 1993;139:49-51.

32. Available from: http://www.healthcare.utah.edu/ huntsmancancerinstitute/cancer/information/resources/ factsheetpdfs/acetic-acid-wound-care.pdf. [Last accessed on 2017 Dec 18]. 